ГЕМОФИЛЬТРАЦИЯ И ГЕМОДИАЛИЗ В ПРОФИЛАКТИКЕ

И ЛЕЧЕНИИ ОСТРОЙ ПОЧЕЧНОЙ НЕДОСТАТОЧНОСТИ ПОСЛЕ ОПЕРАЦИЙ НА СЕРДЦЕ С ИСКУССТВЕННЫМ КРОВООБРАЩЕНИЕМ

\author{
Е. А. Табакьян, С. А. Партигулов, Т. Н. Савушкина, М. Г. Лепилин, Р. С. Акчурин \\ ФГБУ Российский кардиологический научно-производственный комплекс \\ Министерства здравоохранения и социального развития Российской федерации, \\ Институт клинической кардиологии им. А. Л. Мясникова, отдел сердечно-сосудистой хирургии, Москва
}

\title{
Hemofiltration and Hemodialysis in the Prevention and Treatment of Acute Renal Failure after Cardiac Surgery under Extracorporeal Circulation
}

\author{
E. A. Tabakyan, S. A. Partigulov, T. N. Savushkina, M. G. Lepilin, R. S. Akchurin \\ Department of Cardiovascular Surgery, A. L. Myasnikov Institute of Clinical Cardiology, \\ Russian Cardiology Research-and-Production Complex, \\ Ministry of Health and Social Development of the Russian Federation, Moscow
}

\begin{abstract}
Цель исследования - анализ эффективности гемофильтрации (ГФ) на этапе искусственного кровообращения (ИК) при операциях на сердце, для профилактики острого снижения функции почек и развития острой почечной недостаточности (ОПН). Материал и методы. Риск развития после операции ОПН, требующей применения заместительной почечной терапии (ЗПТ), оценивали до операции согласно сумме баллов и процентов риска по Cleveland score (2005). ГФ на этапе ИК применяли у больных высокого риска развития ОПН. Процедуру проводили посредством совмещения 2-х экстракорпоральных контуров: ИК и аппарата Diapact®CRRT. В случае развития ОПН, 3 стадия по Risk, Injury, Failure, Loss of kidney function, End-stage Renal Disease (RIFLE) 2004 и Acute Kidney Injury Network (AKIN) 2007 , после операции с ИК проводили продолжительную вено-венозную гемофильтрацию (ПВВГФ) и продолжительный высокопоточный гемодиализ (ПВГД) в режиме рециркуляции диализата. Для оценки достоверности межгрупповых различий применяли непараметрический метод анализа по Манна-Уитни. Результаты представлены: медиана (нижний квартиль; верхний квартиль), различия считались достоверными при $p<0,05$. Результаты. ГФ на этапе ИК. Шесть больных, возраст 65,5 (57; 70) лет, с хронической болезнью почек (ХБП), скорость клубочковой фильтрации (СКФ) по Кокрофту-Гаулту до операции $50(41,5 ; 65)$ мл/мин/1,73 м². Максимальное снижение СКФ после ИК на 2,9

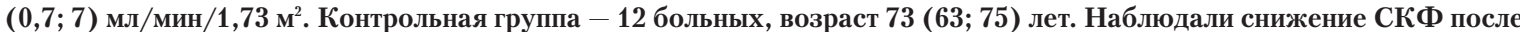
операции на $17(13,7 ; 22)$ мл/мин/1,73 м². У одного пациента контрольной группы развилась ОПН и полиорганная недостаточность (ПОН), потребовалось проведение ПВВГФ и ПВГД. Заключение. Использование интраоперационной гемофильтрации у больных с высоким риском снижения функции почек, вероятно, позволит предотвратить значительное снижение СКФ и развитие ОПН после операций с ИК. Ключевые слова: операции на сердце с искусственным кровообращением, острая почечная недостаточность, гемофильтрация, гемодиализ.
\end{abstract}

Objective: to analyze the efficiency of hemofiltration (HF) in the stage of extracorporeal circulation (EC) during cardiac surgery in order to prevent acute renal function lowering and the development of acute renal failure (ARF). Materials and methods. The risk of postoperative ARF requiring renal replacement therapy (RRT) was preoperatively assessed by the summed Cleveland risk score and percentage (2005). HF during EC was used in patients at high risk for ARF. The procedure was performed, by combining 2 extracorporeal circuits: EC and a Diapact ${ }^{\circledR}$ CRRT apparatus. With evolving ARF, Stage 3 after Risk, Injury, Failure, Loss of Kidney Function, End-stage Renal Disease (RIFLE), 2004, and Acute Kidney Injury Network (AKIN), 2007, continuous venovenous hemofiltration (CVVHF) and continuous high-flow hemodialysis (CHFHD) were done in the dialysate recirculation mode after surgery under EC. The Mann-Whitney nonparametric test was used to estimate the significance of intergroup differences. The results are presented: median (lower quartile; upper quartile), the differences considered to be significant at $p<0.05$. Results. HF during EC; 6 patients were aged 65.5 (range 57-70) years with chronic kidney disease, preoperative glomerular filtration rate (GFR) was 50 (range 41.5-65) $\mathrm{ml} / \mathrm{min} / 1.73 \mathrm{~m}^{2}$ using the Cockroft-Gault formula. The maximum GFR decrease by 2.9 (range 0.7-7) $\mathrm{ml} / \mathrm{min} / 1.73 \mathrm{~m}^{2}$ was seen after EC. A control group comprised 12 patients aged 73 (range 63-75) years. There was a postoperative GFR reduction by 17 (range $13.7-22$ ) $\mathrm{ml} / \mathrm{min} / 1.73 \mathrm{~m}^{2}$. One patient from the control group developed ARF and multiple organ dysfunction, which required CVVHF and CHFHD. Conclusion. The use of intraoperative HF in patients

Адрес для корреспонденции (Correspondence to):

Табакьян Евгений Аведикович

E-mail: tabakyan@mail.ru at high risk for renal function lowering is likely to prevent a considerable GFR reduction and ARF after surgery under EC. Key words: cardiac surgery under extracorporeal circulation, acute renal failure, hemofiltration, hemodialysis. 
ОПН - хорошо известное осложнение после операций на сердце с применением ИК. Распространенность ОПН достигает 30\%, потребность в применении методов ЗПТ составляет 1-8\% от общего числа оперированных пациентов [1-4]. ОПН, как непосредственное следствие ИК, развивается с частотой до $1 \%$ у взрослых пациентов, и достигает 2-10\% у грудных детей [5]. Факторами риска развития ОПН являются снижение функции почек до операции, сахарный диабет, снижение систолической функции миокарда и наличие хронической сердечной недостаточности (ХCH) IIIIV функционального класса (ФК), характер оперативного вмешательства и т. д. Согласно Cleveland score (2005) или Simplified Renal Index (SRI) score Toronto (2007) определяют сумму баллов и процент риска развития ОПН, требующей ЗПТ после операции [6].

Устранение побочных эффектов процедуры ИК возможно при удалении избытка жидкости, увеличении гематокрита пациента с помощью ультрафильтрации. В качестве профилактики ухудшения функции почек, развития послеоперационной ОПН у больных высокого риска предложена интраоперационная ГФ [7]. В случае развития ОПН, процедуры ЗПТ применяют на основании абсолютных показаний и оценки тяжести ОПН согласно классификаций RIFLE (2004), AKIN (2007) [8]. Часто состояние усугубляется присоединением ПОН. Несмотря на применение ЗПТ, смертность данного контингента больных остается высокой - не менее $50 \%$ [9].

Анализ публикаций последних лет указывает на поиск наиболее оптимальных режимов ЗПТ для профилактики и лечения полиорганных нарушений, связанных с проведением операций на открытом сердце [10, 11]. Остаются дискутабельными вопросы длительности и сроков начала процедуры, режимов антикоагуляции, времени функционирования гемофильтра, объёма замещающего раствора в единицу времени и его оптимальный состав, сочетание с проводимой терапией $[9,12,13]$.

В данной работе представлены результаты интраи послеоперационного применения ГФ, ПВВГФ, ПВГД.

\section{Материал и методы}

Целесообразность применения ГФ на этапе ИК определяли на основании: 1) Очень высокого риска послеоперационной ОПН по Cleveland score, 2005 (9-13 баллов - 21,5\%) и Simplified Renal Index (SRI) score, Toronto, 2007 (5 баллов $13-19 \%)$; 2) Высокого риска ОПН (6-8 баллов $-7,8-9,5 \%)$ и ( 4 балла $-5-9 \%$ ) и наличия дополнительных факторов риска: предполагаемая длительность ИК $\geqslant 150$ мин, возраст $\geqslant 70$ лет, предоперационная анемия: гемоглобин $\leqslant 12$ г/л $[6,14]$.

В случае развития ОПН после операций на открытом сердце с ИК целесообразность ЗПТ определяли с учетом абсолютных показаний к применению ЗПТ и при наличии 3 -й стадии ОПН по AKIN (2007) и RIFLE (2004) [8, 15].

Оценку СКФ осуществляли двумя методами: по формуле Кокрофта-Гаулта и Modification of Diet in Renal Disease Study (MDRD) [16].

Для определения электролитов, газов, кислотно-основного состояния, гематокрита и гемоглобина крови использовали анализатор GEM Premier 3000 (Instrumentation Laboratory, США) Для определения активированного времени свертыва- ния (ABC) крови применяли анализатор (Medtronic HemoTec АCT II, США).

Процедуры ЗПТ проводили на аппарате Diapact®CRRT (B.Braun) Германия. Подачу и возврат крови обеспечивали через двухпросветный радиационно-контрастный катетер Haemocat ${ }^{\circledR}$ Signo 12F High Flow 4 мм, длина 17 см (B.Braun), установленный в подключичную вену пациента.

Процедура ПВВГФ. Скорость потока крови 180-250 мл/мин. Использовали высокопоточный диализатор Diacap ${ }^{\circ}$ HI PS 18. Для замещения применяли раствор на основе бикарбонатного буфера Duosol® (B.Braun) с содержанием калия 2 или 4 ммоль/л, в зависимости от уровня калиемии. Объем замещения 30-35 мл/кг/час методом постдилюции.

Процедуру ПВГД проводили в режиме рециркуляции диализата. Использовали диализатор - Diacap® HI PS 18. За счет процесса обратной фильтрации сочетаются преимущества двух принципов транспорта веществ через мембрану: конвекции и диффузии. Скорость потока диализата на основе бикарбонатного буфера составляла 150-200 мл/мин, скорость кровотока 150-200 мл/мин. Время циркуляции - 10 литров pactвора Duosol $®$ с содержанием калия 2 или 4 ммоль/л - 180 мин. Контроль гематокрита, электролитов, кислотно-основного состояния крови каждые 2-3 часа.

Антикоагуляция. В физиологический раствор для заполнения и промывки экстракорпорального контура вводили 5 тыс. ед. гепарина на 1 литр раствора. Системную антикоагуляцию начинали с болюсного введения 2000 ед. гепарина, с последующим переходом на инфузию в дозе 500-1000 ед/час. У пациента с риском кровотечения процедуры проводили с использованием максимально переносимого кровотока, применяли метод фракциональной гепаринизации. Целевое АВС поддерживали на 25\% выше исходного.

Процедуру ИК осуществляли с помощью системы роликовых насосов (Stöckert Instrumente GmbH, Германия), мембранного оксигенатора (Vision CША). Контур ИК заполняли растворами: плазмалит, гелофузин, Рингер, маннитол, натрия гидрокарбонат, калия хлорид. Поддерживали перфузионный индекс $2,4 \pm 0,4$ л/мин $/ \mathrm{m}^{2}$. Возмещение кровопотери после обработки крови на сепараторе Cell Saver System (Hemonetics, США). Доза гепарина - 300 ед/кг; пациентам, находящимся на терапии гепарином до операции - 400 ед/кг. Контроль эффективности гепаринизации по показателю АВС (не ниже 500 сек). После окончания ИК вводили протамин-сульфат - 1 мг на 100 ед введенного гепарина. ГФ на этапе ИК проводили посредством совмещения 2-х экстракорпоральных контуров: ИК и аппарата Diapact ${ }^{\circledR} C R R T$. Подача крови из венозной линии, возврат в peзервуар контура ИК. Использовали диализатор - Diacap® HI PS 18. Постдилюция раствором Duosol $\left(K^{+}-4\right.$ ммоль/л) в дозе 50 мл/кг/час. Контроль гематокрита, электролитов, кислотноосновного состояния крови - каждые 30 минут (см. рисунок).

Статистическая обработка результатов. Для оценки достоверности межгрупповых различий применяли непарный непараметрический метод анализа по Манна-Уитни, досто-

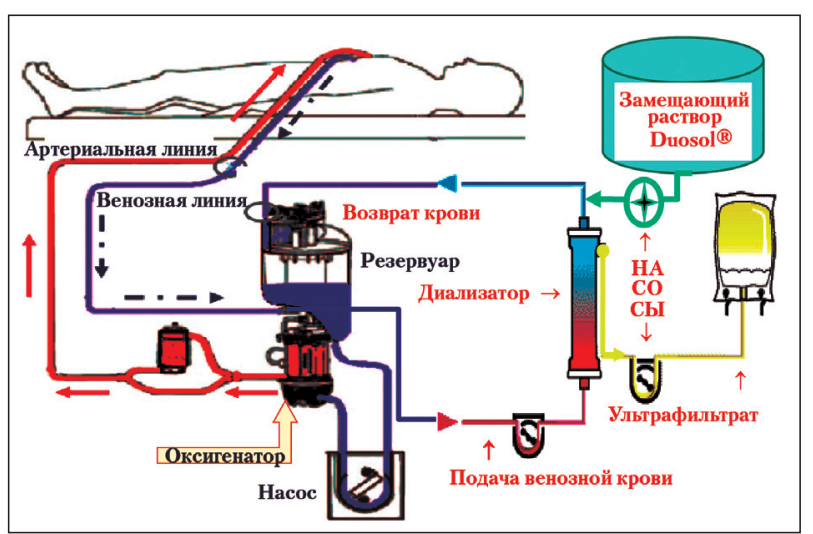

Схема гемофильтрации на этапе ИК. 


\begin{tabular}{|c|c|c|}
\hline \multicolumn{3}{|c|}{ Характеристики пациентов: групाы контроля и ГФ на этапе ИК } \\
\hline \multirow[t]{2}{*}{ Показатель } & \multicolumn{2}{|c|}{ Значения показателей в группах } \\
\hline & $\begin{array}{c}\Gamma \Phi \\
(n=6)\end{array}$ & $\begin{array}{c}\text { контроль } \\
(n=12)\end{array}$ \\
\hline Возраст (лет) & $65,5(57 ; 70)$ & $73(63 ; 75)$ \\
\hline Диабет I или II тип на терапии & $50 \%$ & $50 \%$ \\
\hline Операции: аорто-, маммарокоронарное шунтирование (АКШ, МКШ) & $50 \%$ & $83,3 \%$ \\
\hline Операции: АКШ, МКШ + операции на клапанах или левом желудочке & $50 \%$ & $8,3 \%$ \\
\hline Операции: на клапанах сердца & - & $8,3 \%$ \\
\hline ФК XCH NYHA III & $66,6 \%$ & $25 \%$ \\
\hline Сумма баллов риска развития ОПН, требующей ЗПТ после операции & $4(3 ; 6)$ & $3(3 ; 3,5)$ \\
\hline Предоперационный гемоглобин, г/л & $12,8(12,4 ; 13,1)$ & $13,9(12,8 ; 15,3)$ \\
\hline Длительность ИК, мин & $141(103 ; 150)$ & $103(81 ; 114,5)^{*}$ \\
\hline Креатинин сыворотки, мкмоль/л & $145(120 ; 152)$ & $126(120 ; 143,5)$ \\
\hline СКФ по Кокрофту-Гаулту, мл/мин/1,73 м² & $50(41,5 ; 65)$ & $53(48 ; 57)$ \\
\hline Снижение СКФ после операции по Кокрофту-Гаулту, мл/мин/1,73 м² & $2,9(0,7 ; 7)$ & $17(13,7 ; 22)^{*}$ \\
\hline СКФ по MDRD, мл/мин/1,73 м² & $44,5(43 ; 60)$ & $50(44 ; 54,5)$ \\
\hline Снижение СКФ после операции по MDRD, мл/мин/1,73 м² & $3,5(1 ; 8)$ & $16,5(14,5 ; 23)^{*}$ \\
\hline Максимальный уровень лактата за 24 часа после операции & $2,6(2,1 ; 3,3)$ & $2,7(1,65 ; 2,95)$ \\
\hline
\end{tabular}

Примечание. ${ }^{*}-p<0,05$.

верность различий при $p<0,05$. Результаты представлены в виде: медиана (нижний квартиль; верхний квартиль), процент от общего количества.

\section{Результаты и обсуждение}

Интраоперационное применение ЗПТ. ГФ на этапе ИК проводили с целью профилактики ухудшения функции почек, развития послеоперационной ОПН.

Сформировано 2 группы больных. Группа ГФ на этапе ИК: 6 больных, все мужчины и контрольная группа: ИК без ГФ - 11 мужчин, 1 женщина. Результаты обследования до и после операций представлены в таблице.

У всех больных наблюдали ХБП ІІІ ст. Средние уровни креатинина сыворотки крови, СКФ, возраст достоверно не различались в группах (см. таблицу). Предопеоперационное содержание гемоглобина было ниже в группе ГФ, однако различия недостоверны $(p=0,06)$. В группе контроля отмечали больший процент операций коронарного шунтирования (КШ), достоверно меньшую продолжительность ИК. В группу ГФ включили больных высокого риска ОПН (6-8 баллов - 7,8-9,5\%). При сумме баллов менее 6 принимали во внимание наличие дополнительных факторов риска [14].

За максимальное принимали снижение СКФ за все дни нахождения в стационаре после операции. Снижение СКФ в группе ГФ $<25 \%$, достоверно значительно ниже, чем в группе контроля -> 25\%. Гиперлактатемия наблюдалась в 2-х случаях в каждой группе. Уровни лактата за 24 часа после операции не отличались в группах. В группе ГФ ОПН не наблюдали. Полученные результаты указывают на эффективность интраоперационного применения ГФ для профилактики острого снижения функции почек.

В группе контроля ОПН развилась в 2-х случаях, в одном потребовалось применение ЗПТ. В обоих случаях, до операции сумма баллов по Кливлендской шкале 3 и 4, что соответствует 1,8\% риска развития ОПН, требующей ЗПТ после операции [17]. К дополнительному фактору риска можно отнести возраст $>70$ лет.
В одном случае причиной ОПН у больного 77 лет на 4-е сутки после коронарного шунтирования явилась гипоальбуминемия, гиповолемия, гипотония, коррекция которых привела к восстановлению функции почек. В другом случае, после протезирования аортального клапана у больного 72 лет с диабетической нефропатией, хронической болезнью почек, на 3-и сутки развилось острое повреждение почек смешанного генеза (гиповолемия на фоне диареи, токсемия вследствие колита, предположительно, клостридиальной этиологии). Кроме того, нельзя исключить тромботическую почечную микроангиопатию, ассоциированную с кардиохирургическим вмешательством, тяжесть которой усугубилась на фоне псевдомембранозного колита. Состояние осложнялось присоединением дыхательной, печеночной недостаточности. В течение 10-и дней проведено 5 процедур ЗПТ (2 ПВВГФ длительностью 24 и 17 часов, 3 ПВГД длительностью 8 и 6 часов), наблюдали восстановление функции почек, обратное развитие ОПН. Длительность нахождения в отделении реанимации и интенсивной терапии (ОРИТ) -17 , нахождение в стационаре после операции 35 суток.

Влияние пред- и интраоперационных факторов риска на развитие ОПН после операций на сердце с ИК хорошо известны по результатам предыдущих исследований $[14,18,19]$. Умеренно выраженная почечная недостаточность (повышение уровня креатинина до 1,5 раз, снижение СКФ до 25\%) часто отвечает на адекватную медикаментозную терапию, происходит восстановление функции почек. В небольшом проценте случаев прогрессирует тяжелая ОПН с присоединением ПОН, требующая искусственной вентиляции легких, инотропной поддержки. Летальный исход в этой подгруппе пациентов остается высоким (>60\%) несмотря на применение ЗПТ [20].

У пациентов с дисфункцией почек отмечен повышенный риск смертности в течение месяца и при длительном наблюдении после операций коронарного шунтирования [21,22]. Применение ГФ у пациентов с ХБП 
на этапе ИК показало ее положительное влияние на функцию почек после операции КШ. У пациентов с ХБП ІІІ ст. и подключением ГФ во время ИК, СКФ после КШ снижалась незначительно, была сравнима с таковой при операциях КШ «of pump». В группе ИК без ГФ, СКФ после операции была достоверно ниже [7]. В наше исследование включено меньше пациентов, кроме операций КШ имели место вмешательства на клапанах сердца и левом желудочке, доза замещения несколько больше, чем в приведенном исследовании.

Гиперлактатемия во время и после процедуры ИК отражает несоответствие между доставкой и потребностью тканей в кислороде и определяется, как повышение уровня лактата $>3$ ммоль/л. Установлена корреляция гиперлактатемии с максимальным уровнем креатинина после операции, длительностью искусственной вентиляции легких, нахождения в отделении реанимации [23]. Отсутствие разницы в уровнях лактата за 24 часа после операции между группами можно объяснить сочетанием негативных и позитивных влияний. Во-первых, в группе ГФ у 66,6 \% пациентов наблюдали III ФК ХСН по NYHA, в то время как в группе контроля только в $25 \%$. Негативное влияние ХСН на функцию печени очевидно, при ХCH утилизация лактата нарушена. Во-вторых, длительность ИК в группе ГФ была достоверно больше, что способствовало накоплению лактата. Против указанных отрицательных факторов работала процедура ГФ во время ИК, удаляя лактат, замещая его изоосмолярным раствором гидрокарбоната. ГФ предотвращает развитие дефицита оснований и необходимость его коррекции гиперосмолярным раствором гидрокарбоната натрия.

Кроме того, следует учитывать еще ряд преимуществ ГФ на этапе ИК с использованием аппарата для ЗПТ. В отличие от использования гемоконцентраторов, кровоток осуществляется по вено-венозному контуру, что исключает эффект артерио-венозного шунтирова-

\section{Литература}

1. Rosnerand M. H., Okusa M.D. Acute kidney injury associated with cardiac surgery. Clin. J. Am. Soc. Nephrol. 2006; 1 (1): 19-32.

2. KiloJ., Margreiter J. E., Ruttmann E. et al. Slightly elevated serum creatinine predicts renal failure requiring hemofiltration after cardiac surgery. Heart Surg. Forum 2005; 8 (1): E34-E38.

3. Elahi M. M., Lim M. Y.,Joseph R. N. et al. Early hemofiltration improves survival in post-cardiotomy patients with acute renal failure. Eur. J Cardiothorac. Surg. 2004; 26 (5): 1027-1031.

4. Perez-Valdivieso J. R., Monedero P., Vives M. et al. Cardiac-surgery associated acute kidney injury requiring renal replacement therapy. A Spanish retrospective case-cohort study. BMC Nephrol. 2009; 10: 27.

5. Хенсли Ф. А. -мл., Мартин Д. Е., Гревли Г. П. Практическая кардиоанестезиология. 3-е изд. М.: Медицинское информационное агентство; 2008. 822-857.

6. Candela-Toha A., Elias-Martin E., Abraira V. et al. Predicting acute renal failure after cardiac surgery: external validation of two new clinical scores. Clin. J. Am. Soc. Nephrol. 2008; 3 (5): 1260-1265.

7. Roscitano A., Benedetto U., Goracci M. et al. Intraoperative continuous venovenous hemofiltration during coronary surgery. Asian Cardiovasc. Thorac. Ann. 2009; 17 (5): 462-466.

8. Ricci Z., Romagnoli S., Ronco C. Renal support. Minerva Anestesiol. 2011; 77 (12): 1204-1215.

9. Prowle J. R., Bellomo R. Continuous renal replacement therapy: recent advances and future research. Nat. Rev. Nephrol. 2010; 6 (9): 521-529.

10. Bapat V., Sabetai M., Roxburgh J. et al. Early and intensive continuous veno-venous hemofiltration for acute renal failure after cardiac surgery. Interact. Cardiovasc. Thorac. Surg. 2004; 3 (3): 426-430. ния крови. Введение замещающего раствора Duosol® c содержанием $\mathrm{K}^{+}-4$ ммоль/л, $\mathrm{Ca}^{2+}-1,5$ ммоль/л в дозе замещения 50 мл/кг/час позволяет эффективно поддерживать уровни калий- и кальциемии во время процедуры ИК. Постоянно контролируемый объем ультрафильтрации обеспечивает необходимое удаление избытка жидкой части плазмы крови, увеличение гематокрита без применения петлевых диуретиков. Это представляется важным, так как применение фуросемида не только не улучшает клиренс креатинина после операции, но и может вызывать отчетливое повышение уровня креатинина [24, 25].

Очевидная разница в степени снижения СКФ в группах позволяет сделать предварительный вывод о целесообразности применения ГФ на этапе ИК у пациентов с ХБП и высоким риском развития ОПН. Однако подтверждение полученных результатов возможно при анализе большего числа пациентов.

\section{Заключение}

Приведенные клинические примеры демонстрируют возможность развития ОПН у больных с невысоким предоперационным риском повреждения почек. Развитие ОПН (на 3-и и 4-е сутки после операции) отчасти зависело от послеоперационного состояния гемодинамики. Вероятно, определение в моче биомаркера ранних стадий острого повреждения почек: нейтрофил-желатиназа-ассоциированного липокалина (NGAL) в ранние сроки (через 2-6 часов) после операций с ИК и развития послеоперационных осложнений позволило бы разграничить влияние этих причин на повреждение почек. Большие надежды возлагаются на дальнейшее проведение исследований содержания NGAL в крови и моче для внедрения в практику показаний к началу ЗПТ [26].

11. Lanquetot H., Leprince T., Ragot S. et al. Antithrombin level and circuit thrombosis during hemofiltration after cardiopulmonary bypass. Intensive Care Med. 2008; 34 (11): 2068-2075.

12. Барбараш Л. С., Плотников Г. П., Шукевич Д. Л. и соавт. Обоснование ранней заместительной почечной терапии при полиорганной недостаточности. Общая реаниматология 2010; VI (6): 29-33.

13. Ямпольский М. А., Заболотских И. Б., Ямпольский А. Ф. Элиминация низкомолекулярных белков у больных с изолированной острой почечной недостаточностью. Общая реаниматология 2010; VI (5): $40-45$

14. Karkouti K., Wijeysundera D. N., Yau T. M. et al. Acute kidney injury after cardiac surgery: focus on modifiable risk factors. Circulation 2009; 119 (4): 495-502.

15. Englberger L., Suri R. M., Li Z. et al. Clinical accuracy of RIFLE and Acute Kidney Injury Network (AKIN) criteria for acute kidney injury in patients under going cardiac surgery. Crit. Care 2011; 15 (1): R16.

16. Shara N. M., Resnick H. E., Lu L. et al. Decreased GFR estimated by MDRD or Cockcroft-Gault equation predicts incident CVD: the strong heart study. J. Nephrol. 2009; 22 (3): 373-380.

17. Thakar C. V., Arrigain S., Worley S. et al. A clinical score to predict acute renal failure after cardiac surgery. J. Am. Soc. Nephrol. 2005; 16 (1): 162-168.

18. Dirkes $S$., Hodge K. Continuous renal replacement therapy in the adult intensive care unit: history and current trends. Crit. Care Nurse 2007; 27 (2): 61-80.

19. Cole L., Bellomo R., Davenport P. et al. Cytokine removal during continuous renal replacement therapy: an ex vivo comparison of convection and diffusion. Int. J. Artif. Organs 2004; 27 (5): 388-397. 
20. National Kidney Foundation. K/DOQI clinical practice guidelines for chronic kidney disease: evaluation, classification, and stratification. Am. J. Kidney Dis. 2002; 39 (2 Suppl 1): S1-S266.

21. Hirose H., Amano A., Takahashi A., Nagano N. Coronary artery bypass grafting for patients with non-dialysis-dependent renal dysfunction (serum creatinine $>$ or $=2.0 \mathrm{mg} / \mathrm{dl}$ ). Eur. J. Cardiothorac. Surg. 2001; 20 (3): $565-572$.

22. van de Wal R. M., van Brussel B. L., Voors A. A. et al. Mild preoperative renal dysfunction as a predictor of long-term clinical outcome after coronary bypass surgery. J. Thorac. Cardiovasc. Surg. 2005; 129 (2): $330-335$.
23. Ranucci M., De Toffol B., Isgrò G. et al. Hyperlactatemia during cardiopulmonary bypass: determinants and impact on postoperative outcome. Crit. Care 2006; 10 (6): R167.

24. Lassing A., Donner E., Grubhoter G. et al. Lack of renoprotective effects of dopamine and furosemide during cardiac surgery. J. Am. Soc. Nephrol. 2000; 11 (1): 97-104.

25. Karajala V., Mansour W., Kellum J. A. Diuretics in acute kidney injury. Minerva Anestesiol. 2009; 75 (5): 251-257.

26. Bennett M., Dent C. L., Ma Q. et al. Urine NGAL predicts severity of acute kidney injury after cardiac surgery: a prospective study. Clin. J. Am. Soc. Nephrol. 2008; 3 (3): 665-673.

\section{ОБЩАЯ РЕАНИМАТОЛОГИЯ}

Научно-практический журнал «Общая реаниматология», входящий в перечень ВАК РФ, предназначен для врачей анестезиологов-реаниматологов и научных сотрудников.

Тематика журнала: патогенез, клиника, диагностика, лечение, профилактика и патологическая анатомия критических, терминальных и постреанимационных состояний. Вопросы оказания догоспитальной помощи при критических состояниях. Вопросы обучения населения и медицинского персонала приемам оказания неотложной помощи при критических состояниях.

Аудитория: лечебные учреждения; высшие учебные заведения медицинского профиля; медицинские учреждения последипломного образования, Федеральные и региональные органы управления здравоохранением, медицинские научно-исследовательские институты; медицинские библиотеки.

\section{П О Д П И С К А}

В любом почтовом отделении связи по каталогу «Роспечать»

• индекс 46338 - для индивидуальных подписчиков

• индекс 46339 - для предприятий и организаций

Диссертации на соискание ученой степени доктора наук без опубликования основных научных результатов в ведущих журналах и изданиях, перечень которых утвержден Высшей аттестационной комиссией, будут отклонены в связи с нарушением п. 11 Положения о порядке присуждения ученых степеней.

Перечень журналов ВАК, издаваемых в Российской Федерации по специальности 14.01.20 «Анестезиология и реаниматология», в которых рекомендуется публикация основных результатов диссертаций на соискание ученой степени доктора и кандидата медицинских наук:

- Анестезиология и реаниматология;

- Общая реаниматология. 